\title{
Освещение событий российско-болгарских дипломатических отношений в журнале «Вестник Европы» в 1894-1917 годах
}

\author{
Н.Н. Демьяненко \\ Ленинградский государственный университет имени А.С. Пушкина, \\ Россия, 196605, Санкт-Петербург, г. Пушкин, Петербургское шоссе, д. 10 лит. А \\ E-mail: nik4-demyanenko@yandex.ru
}

\begin{abstract}
Аннотация. В данной статье впервые в отечественной и зарубежной историографии рассматривается отношение одного из ведущих либеральных журналов России «Вестник Европы» к развитию российско-болгарских отношений в период правления Николая II. Автор показывает, как менялось отношение журнала к Болгарии, ее правителям и болгарскому народу в течение более чем двух десятилетий, начиная с периода, когда отношения фактически отсутствовали при Александре III, и с 1896 года, когда отношения были возобновлены, до периода Балканского кризиса и балканских войн. Заканчивается обзор началом Первой мировой войны, когда Болгария после пятнадцати месяцев дипломатической борьбы вошла в стан врагов России. В качестве источников использовались публикации журнала «Вестник Европы» за период с 1894 по 1917 г. Анализ публикаций журнала позволил автору проследить изменение общественного мнения по отношению к Болгарии и болгарам с момента смерти Александра III и до вступления Болгарии в войну на стороне Германии в 1915 г.
\end{abstract}

Ключевые слова: Внешняя политика, Балканы, Македония, Болгария, болгары, Фердинанд I, русско-болгарские отношения, русская печать, «Вестник Европы».

Для цитирования: Демьяненко Н.Н. 2020. Освещение событий российско-болгарских дипломатических отношений в журнале «Вестник Европы» в 1894-1917 годах. Via in tempore. История. Политология, 47 (4): 826-835. DOI: 10.18413/2687-0967-2020-47-4-826-835.

\section{Coverage of the events of Russian-Bulgarian diplomatic relations in the journal «Bulletin of Europe» in 1894-1917}

\author{
Nikolay N. Demyanenko \\ Leningrad state University named after A.S. Pushkin, \\ lit. A 10 Peterburgskoe HWY, Pushkin, Saint Petersburg, 196605, Russia \\ E-mail: nik4-demyanenko@yandex.ru
}

\begin{abstract}
This article discusses the attitude of «Bulletin of Europe», one of the leading liberal magazines in Russia, to the development of Russian-Bulgarian relations during the reign of Nicholas II. The author shows how the magazine's attitude towards Bulgaria, its rulers and the Bulgarian people has changed over more than two decades. In the year of the coronation of Nicholas II, relations between Russia and Bulgaria were restored. It seemed that the Bulgarians would not test further relations between the two countries for strength. However, the events associated with the uprising in Macedonia in 1903 could have led to a major war in Europe. The declaration of independence of Bulgaria in 1908, which took place almost simultaneously with the annexation of Bosnia and Herzegovina by Austria-Hungary, also left many questions, especially among the supporters of Slavic people unity. Finally, the Second Balkan War and the entry of Bulgaria into the First World War on the side of Germany in the autumn of 1915, drew a line under the relations between the two countries, which resumed after a ten-year break in 1896. Considering one of the publications the author shows the transformation of the attitude towards Bulgaria among the moderately liberal strata of society throughout the reign of Nicholas II. The last year of the
\end{abstract}


reign is not taken into account, since after February 1916, Bulgaria was practically not mentioned on the pages of the magazine.

Keywords: Foreign policy, the Balkans, Macedonia, Bulgaria, Bulgarians, Ferdinand I, RussianBulgarian relations, Russian press, «Bulletin of Europe».

For citation: Demyanenko N.N. 2020. Coverage of the events of Russian-Bulgarian diplomatic relations in the journal «Bulletin of Europe» in 1894-1917. Via in tempore. History and political science, 47 (4): 826-835 (in Russian). DOI: 10.18413/2687-0967-2020-47-4-826-835.

Российская печать конца XIX - начала XX вв. отличалась большим разнообразием. Выходило множество газет и журналов как консервативного, так и умереннолиберального направления. Многие из них стали своеобразными вехами в истории отечественной периодической печати. Одним из самых популярных изданий в России, начиная с XIX века, был литературно-политический журнал «Вестник Европы». Издание, существовавшее с 1866 года, продолжало традиции, заложенные еще Н.М. Карамзиным в одноименном журнале, выходившем с 1802 по 1830 гг. С 1866 по 1908 гг. редакторомиздателем журнала был М.М. Стасюлевич. В этот период журнал становится одним из самых уважаемых изданий в первую очередь в умеренно либеральной среде. «Вестник Европы» подробно освящал на своих страницах события как внутренней, так и внешнеполитической жизни. В каждом выпуске, а журнал с 1869 годы выходил ежемесячно, существовал раздел «Иностранное обозрение». В этом разделе давалась оценка текущей политической ситуации на международной арене. Ежегодно в январском номере представлялась расширенная оценка событий всего предыдущего года. Основная масса материалов была посвящена событиям, связанным с главными державами того времени: Англией, Францией, Германией, Австро-Венгрией, Италией и дряхлеющей Османской империей. Реже материал посвящался странам Дальнего Востока и Западного полушария. Регулярно печатались новости с Балканского полуострова.

Балканы для России были одним из главных направлений во внешней политике. Считая себя ответственной за поддержку братьев по «крови» и «вере», Россия старалась играть активную роль старшего брата. Периодически такое навязчивое опекание приводило к охлаждению балканских стран к своей «покровительнице». Одним из самых ярких примеров таких непростых отношений были взаимосвязи с молодым болгарским государством. Созданное благодаря крови 200 тысяч русских солдат, Болгарское княжество в лице своих правителей постепенно, но настойчиво освобождалось от опеки России. В результате к 1886 году отношения между двумя странами были прекращены. Только после смерти императора «Миротворца» в 1894 году начался процесс потепления между двумя странами. В 1896 г. отношения были восстановлены.

Тем не менее на протяжении всего царствования Николая II болгары не раз испытывали российско-болгарские отношения на прочность. Постоянно тлеющий конфликт в Македонии, который с помощью опекаемых в Болгарии комитетов вылился в Илинденское восстание 1903 г. Провозглашение независимости Болгарии в сентябре 1908 года, совпавшее по времени с аннексией Австро-Венгрией Боснии и Герцеговины. Балканские войны и, наконец, вступление Болгарии в Первую мировую войну на стороне Германии.

Хронологические рамки исследования охватывают период со второй половины 1894 г. (время накануне воцарения Николая II) по февраль 1916 г., когда в «Вестнике Европы» были представлены последние аналитические материалы, дающие оценку роли Болгарии в Четверном союзе.

Источниками для данного исследования являются все номера журналов «Вестник Европы» со второй половины 1894 г. по февраль 1916 г. 
Цель исследования - проанализировать отношение журнала к Болгарии и российско-болгарским отношениям от момента восшествия Николая II на престол до разрыва отношений между двумя государствами в 1915 году и вступления Болгарии в войну на стороне Германии. Достижение поставленной цели предполагает решение следующих задач: определить отношение журнала к Болгарии и ее правителям накануне смерти Александра III; проанализировать трансформацию взглядов на Болгарию с момента вступления на престол Николая II до окончания Второй Балканской войны; оценить отношение «Вестника Европы» к Болгарии и ее правителю после вступления последней в Первую Мировую войну на стороне Германии.

Историография, в которой так или иначе освещаются отношения России и Болгарии в конце XIX - начале XX в., достаточно обширна. Огромное количество монографий и статей, диссертаций и докладов - лишнее тому подтверждение. В довоенный период исследования, посвященные взаимоотношениям двух стран, выходили в достаточно критическом ключе [Покровский, 1926; Павлович, 1935]. В послевоенный период исследования были также крайне ангажированы [История Болгарии, 1954; Литаврин, 1987]. Появились исследования, авторы которых использовали в качестве главного источника отечественную печать того времени [Валеев, 1958].

К наиболее интересным работам по русско-болгарским отношениям конца XIX в. можно отнести исследования историка В.И. Косика. Так, проблемам российскоболгарских отношений конца XIX века посвящена диссертация [Косик, 1993] и монография [Косик, 1993]. В отдельном труде автор исследовал отношения с Болгарий с 1878 г. и до наших дней [Косик, 2014].

Были работы, оценивающие отношения как за определенный период правления Николая II [Мартыненко, 1967], так и посвященные отношениям в последней четверти XIX века [Кадиева, 2007]. В отдельных трудах изучалась дипломатическая борьба с Австро-Венгрией за влияние на Болгарию [Дюлгерова, 1985]. Интерес представляют работы, охватывающие все события, связанные с Балканскими войнами [Писарев, 1985]. Изучалось общественное мнение по отношению к болгарам и сербам в 1912-1913 гг. [Гусев, 2015]. Однако, несмотря на обилие литературы, нет отдельного исследования на тему русско-болгарских отношений периода всего правления Николая II в отражении конкретного либерального издания. Данная статья призвана восполнить этот пробел.

В 1894 году, когда на троне еще находился Александр III, болгарская тематика регулярно всплывала в отечественной печати. По большей части новости из этой балканской страны преподносились в негативных тонах. «Лжекнязь» Фердинанд Кобургский является «самозванцем», болгарское правительство «демонстрирует черную неблагодарность своей освободительнице России» и т. д. и т. п. В этом отношении журнал «Вестник Европы» демонстрировал явное уважение к болгарскому народу и ее правителю, отмечая, что и сам болгарский народ, и его князь относятся к русскому народу с уважением и благодарностью [Вестник Европы, 1894. Т. 4, с. 878].

После вступления в октябре 1894 года на престол Николая II болгары начали предпринимать шаги к примирению с Россией. Телеграммы соболезнования, направленные из Софии в Санкт-Петербург 21 октября, не остались не замеченными в печати. Однако общее отношение печати продолжало оставаться прохладным еще многие месяцы. Фердинанд Кобургский воспринимался как политик, которого Россия не признает не при каких обстоятельствах. Между тем «Вестник Европы» однозначно воспринимал болгарского правителя как достойного, отмечая, что те, кто раньше не воспринимал Фердинанда всерьез, уже признают его болгарским князем и призывают наладить отношения с Россией [Вестник Европы, 1895. Т. 2, с. 384].

В июне 1895 г. последовал визит в Санкт-Петербург болгарской делегации во главе с митрополитом Климентом. Болгары возложили венки на могиле Александра III, а через несколько дней были приняты молодым императором Николаем II. В ходе визита болгар- 
ской делегации обсуждались детали возможного примирения. В те же дни из Болгарии пришло неприятное известие о покушении на бывшего главу болгарского правительства Стефана Стамболова. В России отношение к усопшему политику было однозначно негативное. Однако для «Вестника Европы» его роль в укреплении болгарской государственности была очевидна, так как несмотря на его отрицательное отношение к России, Болгария в годы премьерства Стамболова стала занимать прочное и выгодное политическое положение на Балканах [Вестник Европы, 1895. Т. 4, с. 834].

Состоявшееся в январе 1896 г. крещение принца Бориса, крестным отцом которого стал сам Николай II, способствовало началу официального процесса нормализации отношений между Болгарией и Россией. Изменилось и отношение к Болгарии в печати. Многие консервативные газеты, еще вчера ругавшие принца католика, изменяли тональность своих статей. Как писал «Вестник Европы», «примирение с Болгарией свершилось скорее и проще, чем ожидали наши газетные «патриоты» [Вестник Европы, 1896. Т. 2, c. $407-416]$.

После восстановления отношений между двумя государствами болгарская тема на страницах «Вестника Европы» сошла на нет. С февраля 1897 по февраль 1899 года Болгария ни разу не упоминается на страницах журнала.

В конце XIX века одним из главных источников беспокойства на Балканах становится Македония. Нерешенность македонской проблемы еще с Берлинского конгресса представляла серьезную проблему. В Болгарии сочувствовали своим соплеменникам, живущим в разных частях европейской Турции, подвергающимся всяческим гонениям со стороны мусульманской администрации. Активно работали македонские комитеты, возбуждающие население против турецких властей, призывая народ к вооруженному восстанию. Они ожидали от турецкого правительства дарования автономного самоуправления». [Вестник Европы, 1899. Т. 1, с. 815-816]. В любом случае «Вестник Европы» исходил из того, что македонский вопрос нужно решить мирными средствами [Вестник Европы, 1899. Т. 1, с. 815-816].

Не желая втягивания России в войну, «Вестник Европы» все равно настаивал на более твердом слове русского МИДа в македонском вопросе: «Применяя к современному турецкому кризису австрийские охранительные принципы, дипломатия выдвинула на первый план заботу не о прекращении мусульманских насилий в Македонии и Старой Сербии, а об удержании болгар и сербов от заступничества за угнетенных христиан» [Вестник Европы, 1903. Т. 3, с. 339]. При этом в депешах русских консулов наблюдался пессимизм относительно будущего восстания. В своих сообщениях они подвергали сомнению возможность всеобщего восстания и ожидали синхронные вспышки в разных районах трех турецких вилайетов [Вестник Европы, 1903. Т. 3, с. 339].

18 марта 1903 г. произошло покушение на русского консула Г.С. Щербину в Митровице. Выйдя из дома в сопровождении конвоя, консул был встречен солдатомалбанцем, который, делая вид что кланяется, выстрелил в него из ружья и ранил в левый бок навылет. Спустя девять дней Г.С. Щербина умер от ран.

2 августа 1903 года началось Илинденское восстание в Македонии. А уже 8 августа был убит русской консул в Битоле А.А. Ростковский. Как и в случае с Г.С. Щербиной, убийцей оказался турецкий солдат - этнический албанец. Убийство русского консула вызвало возмущение по всей России. В печати было много гневных слов не только в адрес турецких властей, но и российского МИДа: «Снисходительное отношение к убийству Щербины не было правильно понято турками и, быть может, послужило поводом к странному предположению, что России вообще несвойственно заступаться за своих представителей с такой прямолинейной энергией, какую выказывают в подобных случаях другие великие державы» [Вестник Европы, 1903. Т. 5, с. 354-367].

Однако в этот раз Россия не удовлетворилась официальными извинениями турецкого посла. Более того, данное убийство вполне могло привести к войне. Из Севастополя к 
турецким берегам вышла русская эскадра в составе 14 кораблей. Россия выдвинула ряд требований к Турции. Помимо жесткого наказания для всех причастных к убийству русского консула и немедленной строгой кары для всех гражданских и военных чинов, ответственных за убиение российского консула, Россия потребовала безотлагательного назначения иностранных офицеров в состав жандармерии и полиции для необходимого успокоения мирного населения Македонии и введения законного порядка.

Одновременно с выходом русской эскадры из Севастополя русское дипломатическое ведомство обнародовало телеграмму на имя русского дипломатического агента в Болгарии. В ней болгарскому правительству был послан четкий сигнал о том, что деятельность комитетов носит преступный характер, а поощрение их деятельности болгарским правительством лишь обостряет обстановку [Вестник Европы, 1903. Т. 5, с. 354-367]. Таким образом, Россия ясно дала понять, что ответственность за действия комитетов, возбуждающих население Македонии, лежит на Болгарии. Россия, действуя в рамках русско-австрийского соглашения 1897 года, пошла на заключение 20 сентября 1903 года в ходе встречи Николая II с Францем-Иосифом I Мюрцштегского соглашения, погасившего на некоторое время острую фазу конфликта. Учреждение при турецком наместнике должностей русского и австрийского гражданских агентов, реорганизация местной жандармерии под руководством иностранцев и, наконец, разрешение местным христианам занимать административные и судебные должности на территории Македонии должно было снизить градус напряженности. Правда, об автономии не было и речи. Таким образом, вроде бы болгары должны были быть благодарны России. Однако в их глазах авторитет державы, которую они привыкли называть Освободительницей, постепенно падал. Это было связано с тем, что Россия, старательно избегая возникновения крупного вооруженного конфликта на Балканах, оказалась в глазах болгар в одном ряду с европейскими странами, всячески защищающих турецкие интересы. И в первую очередь с Австро-Венгрией [Вестник Европы, 1904. T. 1, c. 383].

С началом русско-японской войны тема Балкан на страницах «Вестника Европы» сошла на нет. С июля 1904 по июнь 1906 года балканские проблемы в журнале ни разу не упоминались. За это время Россия пережила поражение в войне с Японией, революцию 1905 года, манифест 17 октября, созыв и роспуск первой Государственной Думы. После 1905 года «Вестник Европы» стал рупором партии демократических реформ. Поэтому теперь журнал преподносил информацию с учетом внутренних событий и взглядом той либеральной общественности, которую представлял журнал.

Что касается событий на Балканах, то журнал фиксирует изменение в противоборствующих сторонах конфликта в Македонии, где столкновения между восставшим христианским населением с турецкими войсками сменились жестокими стычками греков с болгарами. Регулярно происходили налеты греческих отрядов на болгарские села и наоборот, болгарские вооруженные отряды разоряли населенные пункты с преимущественно греческим населением [Вестник Европы, 1907. Т. 2, с. 387]. Происходили стычки и сербов с болгарами. По сути, в этих столкновениях уже зарождались зерна той ненависти, которая особенно проявилась во время Второй Балканской войны. Также стоит отметить однобокость издания в освещении результатов таких конфликтов. Так, в сводках о погибших мирных жителях упоминаются только болгары. Про погибших других народностей не сказано ни слова [Вестник Европы, 1907. Т. 2, с. 387].

Осенью 1908 года Австро-Венгрия объявила аннексию оккупированной ею же в 1878 году Боснии и Герцеговины. Одновременно Болгария провозгласила свою независимость от Турции. То, что провозглашение независимости совпало с аннексией Боснии, заселенной сербами, дало повод некоторым консервативным изданиям говорить не только о нарушении Берлинского трактата 1878 года, но и о сговоре Фердинанда I с ФранцемИосифом I, а также о предательстве Болгарией всего славянского дела. «Вестник Европы» оправдывал действия Фердинанда, так как «болгарское нарушение Берлинского трактата 
ни имеет ничего общего с австрийским уже потому, что Болгария этого трактата не подписывала и участия в нем не принимала. Для Болгарии нарушение чуждого и враждебного ей международного договора есть акт национального освобождения и торжества» [Вестник Европы, 1908. Т. 6, с. 366].

Провозглашение независимости Болгарии могло привести ее к войне с Турцией. В течение нескольких месяцев шли напряженные переговоры о материальных компенсациях за дань, которую Турция получала от Болгарии от Восточной Румелии, и компенсации за железную дорогу в этой области. В январе 1909 года Россия предложила посреднические услуги в финансовом споре и представила комбинацию, удобную для обеих сторон и не особенно обременительную для нее самой. Турция получила необходимую сумму путем займа, а Болгария стала платить России приблизительно столько, сколько она платила до этого Турции.

С весны 1909 по сентябрь 1912 года интерес к Болгарии снова затихает. В этот период «Вестник Европы» ее практически не упоминает. Между тем в южной части Европы стал меняться баланс сил. В сентябре 1911 года началась итало-турецкая война. В достаточно короткие сроки и без того дряхлая Оттоманская империя была разгромлена. Турция лишилась последних владений в Северной Африке, а также ряда островов в Эгейском море. В 1912 году у Балканских государств созрел план о совместной войне против Турции, пока та еще не заключила мир с Италией [Вестник Европы, 1912, 10, с. 415]. В короткие сроки сформировался военный блок, куда, помимо Болгарии и Сербии, вошли Греция и Черногория. Поначалу «Вестник Европы» разделял скепсис большинства изданий и российских дипломатов о военных возможностях и долговечности этого блока. Целью дипломатов было сохранить status quo на полуострове в случае ожидаемого поражения балканских стран. Считалось, что Порта, даже находясь в критическом положении после поражения от итальянцев, будет не по зубам Балканскому союзу. Но даже если бы и случилось чудо и турки были бы повержены, то после победы великие державы не дадут самостоятельно распоряжаться результатами этих побед [Вестник Европы, 1912, 9, с. 412].

Помимо этого, на Балканах была еще Румыния, которая не имела общей границы с Турцией и, соответственно, не могла быть участником дележа территорий после войны. Бухарест рассчитывал на компенсации за неучастие своей страны в будущей войне за счет Болгарии. Было понятно, что Бухарест своего не упустит [Вестник Европы, 1912, 10, с. 415]. Николай II присвоил королю румын Каролю I чин генерал-фельдмаршала (последний в истории российской армии) в надежде удержать Румынию от агрессивных планов против болгарской Южной Добруджи.

Однако пессимистические ожидания российских и европейских дипломатов были развеяны стремительными победами балканских армий над турками. «Вместо вопроса о турецких реформах внезапно был поставлен вопрос о самом существовании турецкого владычества на Балканском полуострове» [Вестник Европы, 1912, 11, с. 400]. Главную роль в балканских победах журнал отводил в первую очередь болгарам, чьими победами более всего восторгался: «Болгары - под стенами Константинополя! Кто мог это представить месяц тому назад» [Вестник Европы, 1912, 11, с. 400]. Впрочем, надо отметить, что большинство русских изданий с восторгом писали о болгарских победах.

Вскоре горячая фаза почти на всех фронтах закончилась. Продолжалась еще осада Адрианополя, но в Лондоне уже шли переговоры о мире. Комментируя итоги прошедшего 1912 года, «Вестник Европы» с удовлетворением отмечал, что «Балканская война, начатая 15 (2) октября и прерванная перемирием 3 декабря (20 ноября), остается величайшим событием не только истекшего года, но и всей современной эпохи [Вестник Европы, 1913, 1, c. 417]. Когда в марте 1913 г. пал Адрианополь, журнал с восторгом писал: «Вековой восточный вопрос, стоивший народам столько кровавых и материальных жертв, решен окончательно» [Вестник Европы, 1913, 3, с. 402]. 
К сожалению, единство балканских стран продолжалось недолго. Еще не был подписан мирный договор в Лондоне, а победители уже начали предъявлять претензии друг к другу. Сербия и Греция были недовольны чрезмерным усилением Болгарии и разделом в македонских землях. Кроме того, Сербия «благодаря» Австро-Венгрии так и не получила выход к Адриатическому морю. Предусмотренный между Сербией и Болгарией договором от 29 февраля 1912 года русский арбитраж касался только вопросов, предусмотренных в договоре. Однако реальная война заставила сербов предъявить болгарам новые требования по Македонии. Николай II 26 мая отправил Петру I и Фердинанду I одинаковые телеграммы с предложением о посредничестве в переговорах. В этих же телеграммах предстоящая война между вчерашними союзниками была названа «преступной». Болгария формально сообщила о своем согласии на русский третейский суд, но сопровождала это согласие оговоркой, чтобы арбитраж касался только вопросов, указанных в союзном договоре. Сербия требовала полного пересмотра союзного договора. В ночь на 17 июня 1913 года Болгария напала на сербов и греков. Очень скоро Сербия и Греция перешли в наступление. Одновременно в тыл Болгарии ударила Румыния, а чуть позже - и разгромленная перед этим Турция. Описывая эти события, «Вестник Европы» с ужасом констатировал, что идея балканского союза потоплена в крови.

Вскоре в Бухаресте начались мирные переговоры. Освещая их на своих страницах, «Вестник Европы» не скрывал своего разочарования: «С Болгарией случилось то, чего не бывало еще, кажется, во всемирной истории. Достигнув самого блестящего положения, о котором могли только мечтать болгарские патриоты, правительство царя Фердинанда в короткий двухнедельный период потеряло по собственной вине все плоды великих национальных жертв и подвергло страну всем ужасам отчаяния» [Вестник Европы, 1913, 9, с. 393]. В ходе переговоров Россия, стараясь смягчить тяжелые итоги Бухарестского мира, объявила, что не может допустить чрезмерного умаления и унижения Болгарии. Интересно, что во время переговоров Австро-Венгрия разошлась с Германией и проявила солидарность с Россией, заступаясь за Болгарию против сербов, греков и турок [Вестник Европы, 1913, 9, с. 393]. В сентябре был заключен мирный договор с Турцией в Константинополе. Многие журналисты отмечали изменение в отношениях между Болгарий и Турцией: «Недавняя жестокая вражда как будто исчезла, Болгария, разбитая своими коварными союзниками, почувствовала возможность сближения с Турцией на почве совместной активной неприязни к Сербии и Греции» [Вестник Европы, 1913, 10, с. 395-396].

В июле 1914 года началась Первая мировая война. Определившиеся на начальном этапе противники уперлись в линии позиционной войны. Настал период, когда два вражеских блока стали пытаться втянуть на свою сторону соседние, пока еще нейтральные государства. И если одни страны сразу объявили о своем бесспорном нейтралитете, то вторые (Италия, Болгария, Румыния и Греция) фактически стали своим нейтралитетом торговать. В этот период «Вестник Европы» уже не сильно рассчитывал на Болгарию, где правительство Фердинанда «допускало провоз германского оружия через свою территорию, закрывало свои границы для русских пассажиров и даже для врачей и вообще действовало прямо или косвенно против России, хотя и продолжало по внешности держаться нейтралитета» [Вестник Европы, 1914, 10, с. 349-350]. Тем не менее страны Антанты вели активную работу по недопущению Болгарии в лагерь Центральных держав. В частности, Россия обещала Болгарии за ее нейтралитет «осуществление ее национальных идеалов», т. е. «возвращения тех частей Македонии, которые у нее были отобраны Сербией и Грецией». Россия трижды делала Болгарии соответствующее предложение, однако положительного решения в этом вопросе достигнуто не было.

Осенью 1915 года после побед Германии на Восточном фронте Болгария склонилась в своем выборе в пользу Центральных держав. Чтобы укрепить союз между турками и болгарами, последние «при посредничестве Германии завязали переговоры с турками и добились передачи в их руки площади приблизительно в 3000 квадратных километров» 
[Вестник Европы, 1915, 10, с. 353]. Такая подачка со стороны турок для болгарского царя была последним аргументом в пользу вступления в войну на стороне Германии. Уже всего через несколько дней в Болгарии была объявлена мобилизация.

В октябре 1915 года журналу оставалось лишь констатировать, что жребий брошен, и брошен не кем другим, как самим Фердинандом [Вестник Европы, 1915, 10, с. 353]. Перед этим Россия предъявила болгарскому правительству ультиматум с требованием порвать в течение суток с врагами славянства. В этот момент «Вестник Европы» впервые перешел на острую критику болгарского правителя, подчеркивая, что «Кобург снова почувствовал себя прапорщиком австрийской службы и получил по телеграфу поощрение от своего императора. С развязностью покинувшего прежнего барина слуги, он шлет дерзкую ноту в ответ на русский ультиматум» [Вестник Европы, 1915, 10, с. 353].

5 октября 1915 г. Россия объявила Болгарии войну. Журнал с горечью отмечал противоестественность того, что болгары, освобожденные от турецкого ига и еще недавно стоявшие во главе победоносной балканской федерации против Турции, соединились теперь с турками и австро-германцами [Вестник Европы, 1915, 10, с. 353]. После февраля 1916 года Болгария исчезла со страниц «Вестника Европы».

Журнал «Вестник Европы» на протяжении всего рассматриваемого в статье периода демонстрировал исключительно положительное отношение как к личности Фердинанда Кобургского, так и к Болгарии в принципе. Восстановление дипломатических отношений в 1896 году журнал воспринимал как естественный ход вещей. Очень подробно издание фиксировало все новости из Македонии. Отмечалась ведущая роль в этих событиях Болгарии. Журнал приветствовал провозглашение независимости Болгарии в 1908 году. С восторгом издание писало о роли Болгарии в Первой Балканской войне. В этот момент журнал кратковременно идеализировал взаимоотношения между балканскими народами. Вторая Балканская война отразилась глубоким разочарованием на страницах издания по отношению ко всем балканским народам (а не только к болгарам, как было у многих изданий). Описывая события 1914-1915 гг., журнал впервые выступил с серьезной критикой Фердинанда Кобургского, чего не допускал ранее, хотя до тональности многих консервативных изданий «Вестник Европы» так и не скатился. Даже спустя столетие ощущается какая-то интеллигентность данного издания по отношению к своему читателю.

В целом все основные события взаимоотношений между двумя странами нашли свое отражение на страницах «Вестника Европы».

\section{Список литературы}

1. Валеев Л.Б., Никитин С.А., Мартыненко А.К. 1958. Из истории русско-болгарских отношений. М., Академия наук СССР, 292.

2. Вестник Европы. 1894. Т. 4. 8: 878.

3. Вестник Европы. 1895. Т. 2. 3: 384.

4. Вестник Европы. 1895. Т. 4. 8: 834.

5. Вестник Европы. 1896. Т. 2. 3: 407-416.

6. Вестник Европы. 1899. Т. 1. 2: 815-816.

7. Вестник Европы. 1903. Т. 3. 5: 339.

8. Вестник Европы. 1903. Т. 5. 9: 354-367.

9. Вестник Европы. 1904. Т. 1. 1: 383.

10. Вестник Европы. 1907. Т. 2. 3: 387.

11. Вестник Европы. 1908. Т. 6. 11: 366.

12. Вестник Европы. 1912. 9: 412.

13. Вестник Европы. 1912. 10: 415.

14. Вестник Европы. 1912. 11: 400.

15. Вестник Европы. 1913. 1: 417.

16. Вестник Европы. 1913. 3: 402.

17. Вестник Европы. 1913. 9: 393. 
18. Вестник Европы. 1913. 10: 395-396.

19. Вестник Европы. 1914. 10: 349-350.

20. Вестник Европы. 1915. 10: 353.

21. Гусев Н.С. 2015. Болгария и Сербия в русском общественном мнении в период балканских войн 1912-1913: дисс...канд. ист. наук. М., 420.

22. Дюлгерова Н.А. 1985. Политика России и Австро-Венгрии в отношении Болгарии в конце XIX - нач. XX в. (1896-1903) : дис. ... канд. ист. наук. М., 215.

23. История Болгарии. 1954. Под ред. П.Н. Третьякова, С.А. Никитина, Л.Б. Валеева. Т. 1. М., Изд-во АН СССР, 576.

24. Кадиева М.А. 2007. Политика России в отношении Болгарии в последней четверти XIX века Известия вузов. Северо-Кавказский регион. Общественные науки. 3: 37-39.

25. Косик В.И. 1993. Время разрыва. Политика России в болгарском вопросе 1886-1894 гг. М., Ин-т славяноведения и балканистики РАН, 98.

26. Косик В И. 1993. Политика России в Болгарии 1879-1894 гг.: автореф. дис. ... д-ра ист. наук, Российская Академия наук, Ин-т славяноведения и балканистики. М., 32.

27. Косик В.И. 2014. Балканы: «Порвалась цепь великая...» (середина XIX - начало XXI в.). М., Ин-т славяноведения РАН, 272.

28. Краткая история Болгарии. С древнейших времен до наших дней. 1987. Отв. ред. Г.Г. Литаврин. М., Наука, 558.

29. Мартыненко А.К. 1967. Русско-болгарские отношения в 1894-1902 гг. Киев, изд-во Киев. ун-та, 296.

30. Павлович П. 1935. Авантюры русского царизма в Болгарии. М., Соцэкгиз, 240.

31. Писарев Ю.А. 1985. Великие державы и Балканы накануне Первой мировой войны. М., Наука, 286.

32. Покровский М.Н. 1926. Царская Россия в мировой войне. М., Госиздат, 300.

\section{References}

1. Valeev L.B., Nikitin S.A., Martynenko A.K.1958. Iz istorii russko-bolgarskih otnoshenii [From the history of Russian-Bulgarian relations]. Moscow, 292 (in Russian).

2. Vestnik Evropy [Bulletin of Europe] 1894. Vol. 4. 8: 878 (in Russian).

3. Vestnik Evropy [Bulletin of Europe]. 1895. Vol. 2. 3: 384 (in Russian).

4. Vestnik Evropy [Bulletin of Europe]. 1895. Vol. 4. 8: 834 (in Russian).

5. Vestnik Evropy [Bulletin of Europe]. 1896. Vol. 2. 3: 407-416 (in Russian).

6. Vestnik Evropy [Bulletin of Europe]. 1899. Vol. 1. 2: 815-816 (in Russian).

7. Vestnik Evropy [Bulletin of Europe]. 1903. Vol. 3. 5: 339 (in Russian).

8. Vestnik Evropy [Bulletin of Europe]. 1903. Vol. 5. 9: 354-367 (in Russian).

9. Vestnik Evropy [Bulletin of Europe]. 1904. Vol. 1. 1: 383 (in Russian).

10. Vestnik Evropy [Bulletin of Europe]. 1907. Vol. 2. 3: 387 (in Russian).

11. Vestnik Evropy [Bulletin of Europe]. 1908. Vol. 6. 11: 366 (in Russian).

12. Vestnik Evropy [Bulletin of Europe]. 1912. 9: 412 (in Russian).

13. Vestnik Evropy [Bulletin of Europe]. 1912. 10: 415 (in Russian).

14. Vestnik Evropy [Bulletin of Europe]. 1912. 11: 400 (in Russian).

15. Vestnik Evropy [Bulletin of Europe]. 1913. 1: 417 (in Russian).

16. Vestnik Evropy [Bulletin of Europe]. 1913. 3: 402 (in Russian).

17. Vestnik Evropy [Bulletin of Europe]. 1913. 9: 393 (in Russian).

18. Vestnik Evropy [Bulletin of Europe]. 1913. 10: 395-396 (in Russian).

19. Vestnik Evropy [Bulletin of Europe]. 1914. 10: 349-350 (in Russian).

20. Vestnik Evropy [Bulletin of Europe]. 1915. 10: 353 (in Russian).

21. Gusev N.S. 2015. Bolgariya i Serbiya v russkom obschestvennom mnenii v period Balkanskih voin 1912-1913 [Bulgaria and Serbia in Russian public opinion during the Balkan wars of 1912-1913]. Diss ... Cand. ist. nauk. M., 420 (in Russian).

22. Dyulgerova N.A. 1985. Politika Rossii i Avstro-Vengrii v otnoshenii Bolgarii v kontse XIX - nachale XX veka (1896-1903) [Policy of Russia and Austria-Hungary in relation to Bulgaria at the end of the XIX - beginning XX century (1896-1903)]. Dis. ... kand. ist. nauk. M., 215 (in Russian). 
23. Istoriya Bolgarii 1954. Pod redaktsiej P.N. Tretyakova, S.A. Nikitina, L.B. Valeeva [History of Bulgaria]. T. 1. M. Ed. of the USSR Academy of Sciences, 576 (in Russian).

24. Kadieva M.A. 2007. Politika Rossii v otnoshenii Bolgarii v poslednej chetverti devyatnadtsatogo veka [Policy of Russia towards Bulgaria in the last quarter of the nineteenth century]. Izvestiya vuzov. North Caucasus region. Social science. 3: 37-39 (in Russian).

25. Kosik V.I. 1993. Vremya razryva: politika Rossii v bolgarskom voprose 1886-1894 [time of rupture. Russia's policy in the Bulgarian question, 1886-1894]. M., Institute of Slavic and Balkan studies, RAS, 98 (in Russian).

26. Kosik V.I. 1993. Russkaya Politika v Bolgarii 1879-1894 [Policy of Russia in Bulgaria 1879-1894]. Autoref. dis. ... doctor of historical Sciences, Russian Academy of Sciences, Institute of Slavonic studies and balkanistics, Moscow, 32 (in Russian).

27. Kosik V.I. 2014. Balkany: «Porvalas' Tsep' Velikaya...» (seredina XIX - nachalo XX veka) [the Balkans: «The great chain Broke...» (mid-XIX - early XXI century)]. Moscow Institute of Slavonic studies of the Russian Academy of Sciences, 272 (in Russian).

28. Kratkaya istoriya Bolgarii. 1987. S drevneishih vremen do nashih dney [A short history of Bulgaria. From ancient times to the present day]. Ed. by G.G. Litavrin, M., Nauka, 558 (in Russian).

29. Martynenko A.K. 1967. Rossijsko-Bolgarskie otnosheniya v 1894-1902 [Russian-Bulgarian relations in 1894-1902]. Kiev, publishing house of Kiev. un-ta, 296 (in Russian).

30. Pavlovich P. 1935. Avantury Russkogo Tsarisma v Bolgarii [Adventures of Russian tsarism in Bulgaria]. M. Sotsekgiz, 240 (in Russian).

31. Pisarev Yu.A. 1985. Velikije derzhavy i Balkany nakanune Pervoy Mirovoy Voiny [Great powers and the Balkans on the eve of the First world war]. M., Nauka, 286 (in Russian).

Pokrovsky M.N. 1926. Tsarskaya Rossiya v mirovoy voine [Tsarist Russia in World War]. M., Gosizdat, 300 (in Russian).

\section{ИНФОРМАЦИЯ ОБ АВТОРЕ}

Демьяненко Николай Николаевич, аспирант кафедры истории России Ленинградского государственного им. А.С. Пушкина, г. Пушнин, государственного бюджетного общеобразовательного учреждения средняя общеобразовательная школа № 412 Петродворцового района Санкт-Петербурга, Россия

\section{INFORMATION ABOUT THE AUTHOR}

Nikolai N. Demyanenko, postgraduate student of the Department of Russian History, Leningrad State University A.S. Pushkin, St. Petersburg, Pushkin, Russia, history teacher of the state budgetary educational institution, secondary school No. 412 of the Petrodvorets district of St. Petersburg, Russia 